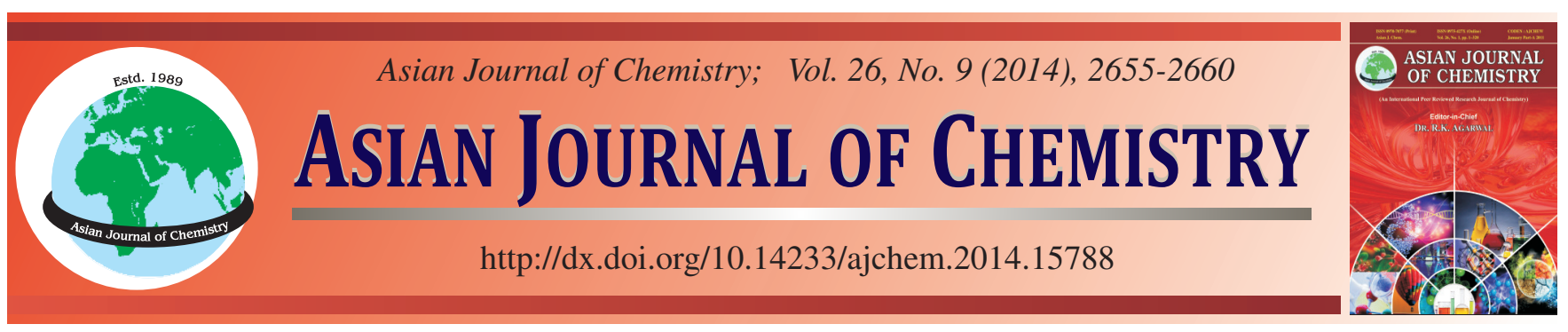

\title{
Effect of pH, Ionic Strength and Heavy Metal Ions on $p$-Nitrophenol Adsorption by Variable Charge Soil of South China
}

\author{
J.Y. ZHANG ${ }^{1}$, C.D. Wu ${ }^{1,2, *}$ and Z.L. ZHANG ${ }^{1}$
}

${ }^{1}$ School of Environment and Energy, South China University of Technology, Guangzhou 510006, P.R. China

${ }^{2}$ The Key Laboratory of Pollution Control and Ecosystem Restoration in Industry Clusters of Ministry of Education, Guangzhou 510006, P.R. China

*Corresponding author: Fax: +86 20 39380508; Tel: +86 20 87110004; E-mail: ppchdwu@ scut.edu.cn

\begin{abstract}
The adsorption behaviour of $p$-nitrophenol on variable charge soil was studied in simulated micropolluted surface water through batch adsorption experiments. It was observed that the adsorption of $p$-nitrophenol decreased with increasing the $\mathrm{pH}$ values of solution, whereas it increased with increasing of ionic strength content, temperature and adsorbent dose and the presence of heavy metal ions depressed the adsorption of $p$-nitrophenol. Langmuir and Freundlich models were used to describe the adsorption isotherms. Results indicated that Freundlich model was fit to experimental data well, revealing the possibility of more than just one monomolecular layer of coverage on the soil surface. The pseudo-first-order and pseudo-second-order kinetic model were applied to describe the kinetic data. The experimental data agreed with pseudo-second-order kinetic model well. Scanning electron microscope and Fourier transform infrared spectroscopy were used to characterize the soil before and after adsorption of $p$-nitrophenol.
\end{abstract}

Keywords: Adsorption, $p$-Nitrophenol, Ionic strength, Variable charge soil.

\section{INTRODUCTION}

During the past few decades, there has been growing concern for public health and environmental safety. Introduction of toxic contaminants can have a severe effect on aquatic ecosystem. $p$-Nitrophenol (PNP) is an important organic intermediate and also environmentally relevant pollutant, which has served as a precursor of dye pharmaceuticals, pesticides and resins ${ }^{1,2}$. Diesel fuel and gasoline exhaust also contain $p$ nitrophenol that enters surface water and groundwater through rainwater ${ }^{3}$. In consideration of the hazardous effects of $p$-nitrophenol on human health at low concentrations, $p$-nitrophenol has been selected as one of the persistent, bioaccumulative and toxic pollutants by the US Environmental Protection Agency ${ }^{4}$. Hence, the removal of $p$-nitrophenol from the surface water, especially acted as raw water for drinking water treatment, is critical to ensure the safety of water supplies. Recently, a considerable effort has been made concerning the removal of $p$-nitrophenol from wastewater. Several methods and technologies have been developed, such as advanced oxidation processes $^{5-7}$, biodegradation ${ }^{8}$, adsorption ${ }^{9-15}$ and the most extensively used method was adsorption process. Various types of adsorbent, such as activated carbon ${ }^{9,10}$, organoclays ${ }^{11}$, palygorskite $^{12,13}$, sediment ${ }^{14,15}$, have been developed.

Variable charge soils (including oxisols, ultisols, inceptisols and alfisols), distributed in the tropical and subtropical regions in South China, generally have low surface charge density with predominant $\mathrm{pH}$-dependent charge $\mathrm{e}^{16,17}$. They are rich in iron and aluminum oxides because of intensive weathering and eluviation and these soils usually carry both positive and negative charges on their surfaces and thus can adsorb both anions and cations ${ }^{18}$. The major factors determining this variable charge include $\mathrm{pH}$, ionic strength, nature of the electrolyte ion and metals and ligands in the soil solution.

Previous studies focusing on the adsorption of heavy metals onto variable charge soils found that adsorption was greatly influenced by $\mathrm{pH}$, ionic strength, nature of the electrolyte ion, metals and organic acids ${ }^{19-23}$. However, few studies about the adsorption of the $p$-nitrophenol onto variable charge soil were reported. Therefore, the objective of this study was to investigate the effect of $\mathrm{pH}$, ionic strength and heavy metals on the adsorption of $p$-nitrophenol onto variable charge soils. Isotherm and kinetic studies were carried out. Moreover, to trace the mechanism, variable charge soil has been characterized before and after the adsorption of $p$-nitrophenol.

\section{EXPERIMENTAL}

Soil characteristics: The adsorption behaviour of $p$-nitrophenol was studied on a variable charge soil collected from Xuwen, Guangdong Province, China. The soil sample was collected from a depth of $20-40 \mathrm{~cm}$ within the profile, air dried 
at room temperature, gently crumbled and passed a 60-mesh sieve to remove stone, plant roots and other large particles and stored in glass bottles for the experimental use. The point of zero net charge $\left(\mathrm{pH}_{\mathrm{PZC}}\right)$ of soil was measured by the method of Babic et al. ${ }^{24}$. Selected properties of the soil studied are given in Table-1. The concentration of the background electrolyte $\left(\mathrm{KNO}_{3}\right)$ used was $0.1 \mathrm{mmol} / \mathrm{L}$.

\begin{tabular}{lc}
\multicolumn{2}{c}{ TABLE-1 } \\
\multicolumn{2}{c}{ PROPERTIES OF THE VARIABLE CHARGE SOIL } \\
\hline \multicolumn{1}{c}{ Property } & Value \\
\hline $\mathrm{pH}^{\mathrm{a}}$ & 5.20 \\
Organic matter $^{\mathrm{b}}(\mathrm{g} / \mathrm{kg})$ & 13.8 \\
$\mathrm{Cation}$ exchange capacity ${ }^{\mathrm{c}}(\mathrm{cmol} / \mathrm{kg})$ & 7.15 \\
$\mathrm{pH}_{\mathrm{PZC}}$ & 4.57 \\
$\mathrm{Fe}_{2} \mathrm{O}_{3}{ }^{\mathrm{d}}(\%)$ & 12.59 \\
$\mathrm{Al}_{2} \mathrm{O}_{3}{ }^{\mathrm{d}}(\%)$ & 21.67 \\
Dominant clay mineral $^{\mathrm{a}}$ Dichromate method. ${ }^{\mathrm{b}}$ Soil:water was & $\mathrm{K}, \mathrm{G}, \mathrm{H}, \mathrm{Go}$ \\
\hline method. ${ }^{\mathrm{d}} \mathrm{DCB}$ method. ${ }^{\mathrm{c}} \mathrm{Ammonium}$ acetate \\
goethite.
\end{tabular}

All of the reagents used were A.R. grade and without further purification. $\mathrm{HNO}_{3}, \mathrm{KOH}$ and $\mathrm{KNO}_{3}$ were purchased from Nanjing chemical reagent Co., China. $p$-Nitrophenol was provided by Shanghai reagent Co., China. Its solubility in water was $16000 \mathrm{mg} / \mathrm{L}$ with a $\mathrm{pK}_{\mathrm{a}}$ value of $7.15 . \mathrm{Zn}\left(\mathrm{NO}_{3}\right)_{2}, \mathrm{~Pb}\left(\mathrm{NO}_{3}\right)_{2}$ and $\mathrm{Cd}\left(\mathrm{NO}_{3}\right)_{2}$ were of all G.R. grade. Deionized water was used for all experiments.

Adsorption studies: In batch adsorption experiments, certain amounts of variable charge soil were added into several $250 \mathrm{~mL}$ Erlenmeyer flasks, each containing $100 \mathrm{~mL}$ solution. The flasks were shaken at $200 \mathrm{r} / \mathrm{min}$ in a Constant Temperature Shaker (Shanghai Scientific Instrument Co. Ltd., China) at a pre-settled temperature $298 \mathrm{~K}$ for $2 \mathrm{~h}$, as preliminary studies suggested that it was enough time to obtain equilibrium. Samples were filtered through a $0.45 \mu \mathrm{m}$ cellulose acetate membrane filter and the equilibrium concentrations of $p$-nitrophenol in the aqueous phase were determined.

The effect of $\mathrm{pH}$ on $p$-nitrophenol adsorption onto variable charge soils was studied by adjusting the $\mathrm{pH}$ of $p$-nitrophenol solutions with dilute $\mathrm{HNO}_{3}$ or KOH solution at $298 \mathrm{~K}$. The influence of $\mathrm{KNO}_{3}$ on the adsorption was also studied. Variable charge soil $(1.0 \mathrm{~g})$ was introduced to $100 \mathrm{~mL} 0.1 \mathrm{mmol} / \mathrm{L} p$ nitrophenol solution at 288, 298 and $308 \mathrm{~K}$, respectively, in order to determine temperature on $p$-nitrophenol adsorption. In kinetic studies, batch experiments were conducted at different periods by adding 0.50 and $1.00 \mathrm{~g}$ variable charge soils into each $100 \mathrm{~mL}$ solution, respectively, at pH 5.0 and $298 \mathrm{~K}$.

The adsorbent phase concentrations of $p$-nitrophenol $\left(\mathrm{q}_{\mathrm{e}}\right)$ were calculated by eqn. 1 :

$$
\mathrm{q}_{\mathrm{e}}=\frac{\mathrm{V}\left(\mathrm{C}_{0}-\mathrm{C}_{\mathrm{e}}\right)}{\mathrm{W}}
$$

where $\mathrm{C}_{0}$ and $\mathrm{C}_{\mathrm{e}}$ are the initial and equilibrium concentrations of $p$-nitrophenol (mg/L), respectively, $\mathrm{V}$ is the volume of the solution (L) and $\mathrm{W}$ is the mass of adsorbent $(\mathrm{g})$.

Characterization of the soil: An S-3700N scanning electron microscope (SEM) (JEOL, Japan) was used visualize the surface morphology and structure of soil before and after adsorption of $p$-nitrophenol.
In Fourier transform infrared spectroscopy (FTIR) analysis, $1.0 \mathrm{mg}$ of the slightly ground soil was gently mixed with 200 mg of oven-dried (at $378 \mathrm{~K}$ ) $\mathrm{KBr}$ and then the mixture was pressed into a pellet. FTIR spectra of the soil was recorded using a Vector-33 Fourier-transform infrared (Bruker Optics Inc., Germany), scanning from 4000 to $500 \mathrm{~cm}^{-1}$ at a resolution of $4 \mathrm{~cm}^{-1}$.

Analysis: The concentrations of $p$-nitrophenol were analyzed by UV-visible spectrophotometer (UV-5800, China) that gave good linearity for the absorbency versus $p$-nitrophenol concentration at its maximum absorbance wavelength $317 \mathrm{~nm}$. In order to keep $p$-nitrophenol in the molecular state, the $\mathrm{pH}$ values of the analyte solutions were fixed at 3.5-4.0. This method has a detection limit of $0.05 \mathrm{mg} / \mathrm{L}$.

\section{RESULTS AND DISCUSSION}

Effect of $\mathbf{p H}$ on adsorption: The influence of $\mathrm{pH}$ on the adsorption of $p$-nitrophenol onto soil was studied and the results were shown in Fig. 1. It was noted from the Fig. 1 that when $\mathrm{pH}$ of the solution was lower than 4.6, the adsorption amount gradually decreased; while the solution $\mathrm{pH}$ increased to higher than 4.6, the adsorption amount obviously decreased. Additionally, it could be also observed that the zeta potential decreased with increasing the solution $\mathrm{pH}$. The degree of protonation of $p$-nitrophenol ( $\left.\varphi_{\text {ions }}\right)$ was calculated by eqn. 2 :

$$
\varphi_{\text {ions }}=\frac{1}{1+10^{\left(\mathrm{pK}_{\mathrm{a}}-\mathrm{pH}\right)}}
$$

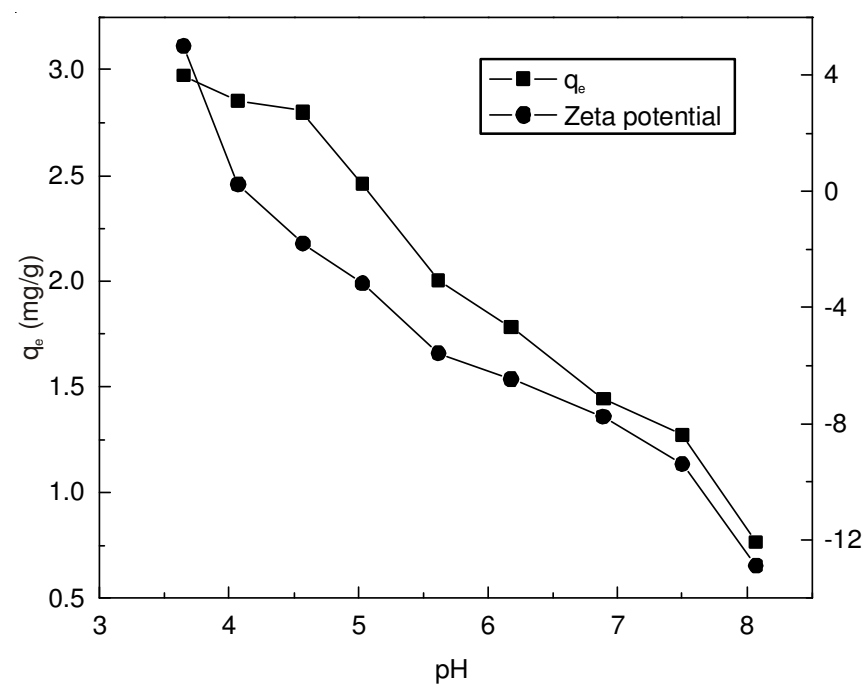

Fig. 1. Influence of $\mathrm{pH}$ on the $p$-nitrophenol adsorption. (Experimental conditions: $\mathrm{C}_{0}, 0.1 \mathrm{mmol} / \mathrm{L}$; variable charge soil, $1.0 \mathrm{~g}$; V, $100 \mathrm{~mL}$; $\mathrm{KNO}_{3}, 0.1 \mathrm{mmol} / \mathrm{L} ; \mathrm{T}, 298 \mathrm{~K}$; agitation rate, $200 \mathrm{r} / \mathrm{min}$; contact time, $2 \mathrm{~h}$ )

Obviously, $\varphi_{\text {ions }}$ increases as the $\mathrm{pH}$ value increased. Considering $\mathrm{pK}_{\mathrm{a}}$ of 7.15 of $p$-nitrophenol, it appeared that $p$ nitrophenol almost present in neutral form when $\mathrm{pH}$ was less than 4.6 which was nearly consistent with $\mathrm{pH}_{\mathrm{PZC}}$ (4.57). At a $\mathrm{pH}$ greater than the $\mathrm{pH}_{\mathrm{PZC}}$ of soil, the surface of the soil is negatively charged and above the $\mathrm{pK}_{\mathrm{a}}$ of the solute, $p$-nitrophenol exists mainly in the ionic form. As the solution $\mathrm{pH}$ increased, the concentration of the anionic form of $p$-nitrophenol increased. However, decreasing negative charge of soil 
would result in high electrostatic repulsion between the surface of soil and the $p$-nitrophenol anions. Hence, $p$-nitrophenol anions could not pack together densely on the surface and the equilibrium amount of the adsorbed $p$-nitrophenol was decreased.

Effect of presence of $\mathrm{KNO}_{3}$ on adsorption: Fig. 2 showed the adsorption of $p$-nitrophenol at different ionic strengths. Under experimental conditions, $p$-nitrophenol molecules almost existed in the molecular state. As shown in Fig. 2a, the equilibrium adsorption amount increased with increasing $\mathrm{KNO}_{3}$ content. This phenomenon could be explained from two aspects. On one hand, it may be ascribed to salting-out effect. Turner and Rawling ${ }^{25}$ have explained this effect that aqueous solubility of neutral organic compounds play an adverse dependency on ionic strength. Water in the presence of dissolved ions was less ordered and less compressible and the cavity volume available to accommodate $p$-nitrophenol molecules was reduced ${ }^{26}$. Hence, $p$-nitrophenol solubility decreased with increasing $\mathrm{KNO}_{3}$ content in the solution. The less soluble the adsorbate became, the more adsorbable it grew. On the other hand, the negative charge of soil decreased as $\mathrm{KNO}_{3}$ content increased (Fig. 2b). As a result, electrostatic repulsion between surface of soil and the $p$-nitrophenol anions decrease, which enhanced the amount adsorption of $p$-nitrophenol.
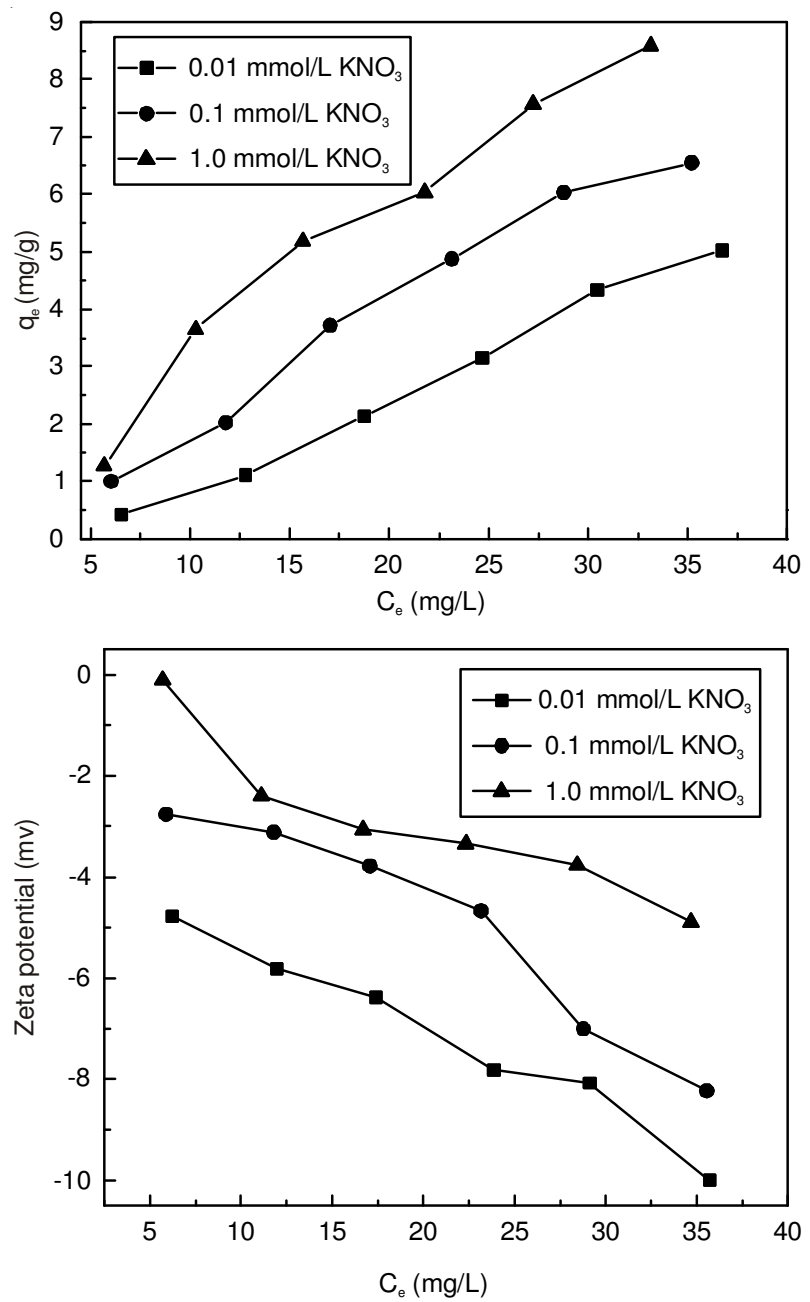

Fig. 2. Comparison of $p$-nitrophenol adsorption performances in different $\mathrm{KNO}_{3}$ content (a-adsorption curves, b-Zeta potential curves). (Experimental conditions: variable charge soil, $1.0 \mathrm{~g} ; \mathrm{V}, 100 \mathrm{~mL}$; $\mathrm{KNO}_{3}, 0.1 \mathrm{mmol} / \mathrm{L} ; \mathrm{T}, 298 \mathrm{~K} ; \mathrm{pH}, 5.0$; agitation rate, $200 \mathrm{r} / \mathrm{min}$; contact time, $2 \mathrm{~h}$ )
Effect of different metal ions on adsorption of $p$-nitrophenol: The effect of metal ions $\left(\mathrm{Cd}^{2+}, \mathrm{Pb}^{2+}, \mathrm{Zn}^{2+}\right)$ on the adsorption of $p$-nitrophenol onto soil was shown in Fig. 3. From Fig. 3, the adsorption of $p$-nitrophenol on soils was diminished significantly in the presence of $\mathrm{Pb}^{2+}, \mathrm{Cd}^{2+}$ and $\mathrm{Zn}^{2+}$ and the order of the inhibiting effect of the three heavy metal ions were as follows: $\mathrm{Pb}^{2+}>\mathrm{Cd}^{2+}>\mathrm{Zn}^{2+}$, which was consistent with hydration enthalpies $\left(\mathrm{Pb}^{2+}=-1481 \mathrm{~kJ} / \mathrm{mol}, \mathrm{Cd}^{2+}=-1807 \mathrm{~kJ} /\right.$ $\left.\mathrm{mol}, \mathrm{Zn}^{2+}=-2046 \mathrm{~kJ} / \mathrm{mol}\right)$ as well as the hydrated radius $\left(\mathrm{Pb}^{2+}\right.$ $\left.=0.401 \mathrm{~nm}, \mathrm{Cd}^{2+}=0.426 \mathrm{~nm}, \mathrm{Zn}^{2+}=0.430 \mathrm{~nm}\right)$. The results could be explained as follows: (1) lower hydration energy facilitated the cation to shed its hydration shell ${ }^{14}$; (2) Smaller hydrated radius led to greater electrostatic attraction ${ }^{27}$.

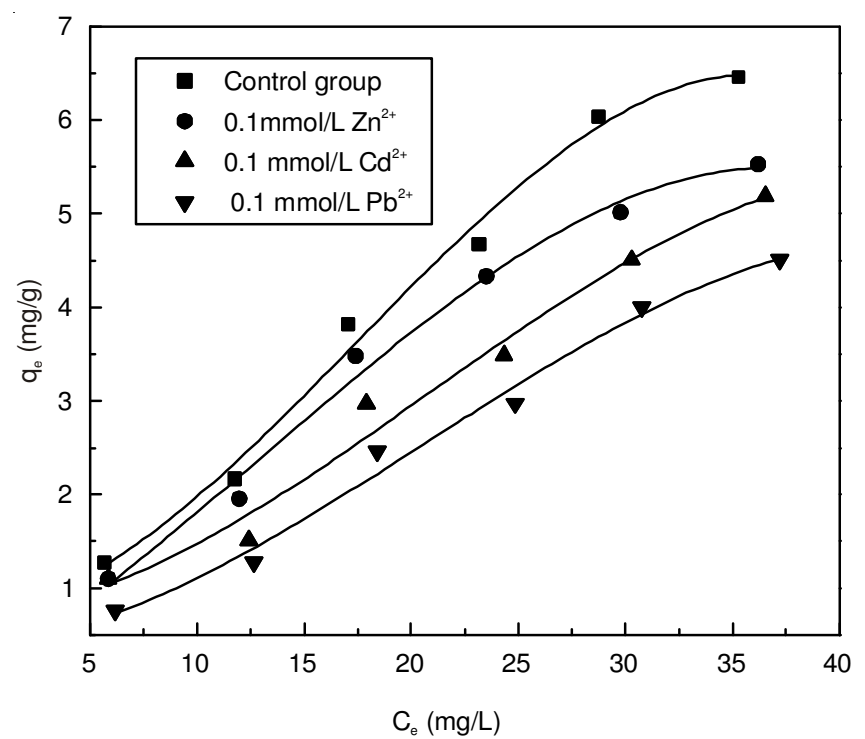

Fig. 3. Effect of $\mathrm{Pb}^{2+}, \mathrm{Cd}^{2+}$ and $\mathrm{Zn}^{2+}$ on the $p$-nitrophenol adsorption. (Experimental conditions: variable charge soil, $1.0 \mathrm{~g} ; \mathrm{V}, 100 \mathrm{~mL}$; $\mathrm{T}, 298 \mathrm{~K} ; \mathrm{Pb}^{2+}, \mathrm{Cd}^{2+}$ and $\mathrm{Zn}^{2+}, 0.1 \mathrm{mmol} / \mathrm{L} ; \mathrm{pH}, 5.0$; agitation rate, $200 \mathrm{r} / \mathrm{min}$; contact time, $2 \mathrm{~h}$ )

Adsorption isotherms: The isothermal adsorption curves of $p$-nitrophenol onto soil were depicted in Fig. 4. For each isotherm, the equilibrium adsorption capacity onto soil increased with an increase equilibrium concentration, because driving force of adsorption increased as the equilibrium concentration increase. Additionally, the equilibrium adsorption capacity was also found to increase with the increase of the temperature, which was attributed to the exothermic nature of the adsorption reaction.

The results were analyzed with the well-known of Langmuir and Freundlich models. The Langmuir isotherm equation (eqn. 3$)^{28}$ and Freundlich isotherm equation (eqn. $4)^{29}$ can be expressed as follows:

$$
\begin{gathered}
\frac{1}{q_{e}}=\frac{1}{b^{0} C_{e}}+\frac{1}{q^{0}} \\
\log q_{e}=\log K_{F}+\frac{1}{n} \log C_{e}
\end{gathered}
$$

where $\mathrm{q}_{\mathrm{e}}$ is the amount of adsorbate taken up on adsorbent at equilibrium ( $\mathrm{mg} / \mathrm{g}), \mathrm{C}_{\mathrm{e}}$ is the equilibrium concentration of the adsorbate in aqueous solution $(\mathrm{mg} / \mathrm{L}), \mathrm{q}^{0}$ and $\mathrm{b}$ are the Langmuir constants related to maximum adsorption capacity 




Fig. 4. Adsorption isotherms of $p$-nitrophenol onto soil at different temperature. (Experimental conditions: variable charge soil, $1.0 \mathrm{~g}$; $\mathrm{V}, 100 \mathrm{~mL}$; pH, 5.0; agitation rate, $200 \mathrm{r} / \mathrm{min}$; contact time, $2 \mathrm{~h}$

and energy of adsorption, respectively, $\mathrm{K}_{\mathrm{F}}$ is the Freundlich constant for a heterogeneous adsorbent and $\mathrm{n}$ is related to the magnitude of the adsorption driving force and to the adsorbent site energy distribution.

The constants calculated according to Langmuir and Freundlich models were given in Table-2. Based on the correlation coefficients $\left(\mathrm{R}^{2}\right)$ obtained, the Freundlich model was better than Langmuir model in describing the behaviour of $p$-nitrophenol adsorption onto the variable charge soil. Langmuir model assumes uniform energies of adsorption onto the surface of the adsorbent with no transmigration of adsorbate in the plane of the surface and the adsorbed molecules have no interaction ${ }^{30}$. The data did not present a good fit to the Langmuir model, while it was consistent with Freundlich model, indicating that surface energies of the soil were not uniform. In this case, some sites were highly energetic and bound the adsorbed $p$-nitrophenol strongly, while some were much less energetic and bound $p$-nitrophenol weakly, which led to the possibility of more than just one monomolecular layer of coverage on the soil surface. Thus, the adsorption of $p$-nitrophenol in multimolecular layers was indicated in view of the experimental data.

\begin{tabular}{cccc|ccc}
\multicolumn{7}{c}{ TABLE-2 } \\
ISOTHERM PARAMETERS OF LANGMUIR AND \\
FREUNDLICH MODEL FOR THE ADSORPTION \\
OF $p$-NITRO PHENOL ONTO SOIL \\
\hline \multirow{2}{*}{$\mathrm{T}(\mathrm{K})$} \\
\cline { 2 - 7 } & $\mathrm{q}^{0}$ & $\mathrm{~b}$ & $\mathrm{R}^{2}$ & $\mathrm{~K}_{\mathrm{F}}$ & $\mathrm{n}$ & $\mathrm{R}^{2}$ \\
\hline 288 & 20.30 & 0.0093 & 0.92 & 0.45 & 1.00 & 0.96 \\
298 & 12.51 & 0.022 & 0.92 & 0.58 & 1.15 & 0.95 \\
308 & 13.04 & 0.033 & 0.93 & 0.76 & 1.32 & 0.96 \\
\hline
\end{tabular}

Adsorption kinetics: Fig. 5 showed the effect of contact time on the adsorption capacity of $p$-nitrophenol on the soil. As shown in Fig. 5, qe increased within $0.5 \mathrm{~h}$ and then it continued to increase at a relatively low speed with contact time until equilibrium reached at $2.0 \mathrm{~h}$ and almost remained constantly. It was also shown that the equilibrium adsorption amount of 0.50 and $1 \mathrm{~g}$ soil were 2.109 and $1.595 \mathrm{mg} / \mathrm{g}$, respectively.

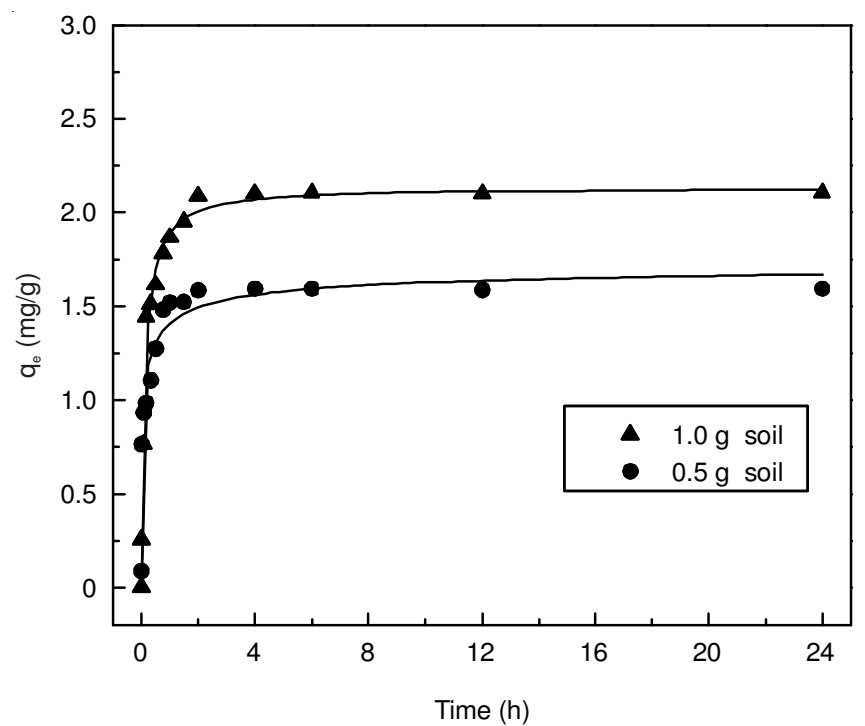

Fig. 5. Plot of $\mathrm{q}_{\mathrm{t}}$ versus time for the adsorption of $p$-nitrophenol at various soil doses. (Experimental conditions: variable charge soil, $1.0 \mathrm{~g}$; $\mathrm{C}_{0}, 0.1 \mathrm{mmol} / \mathrm{L} ; \mathrm{V}, 100 \mathrm{~mL} ; \mathrm{T}, 298 \mathrm{~K} ; \mathrm{KNO}_{3}, 0.1 \mathrm{mmol} / \mathrm{L} ; \mathrm{pH}, 5.0$; agitation rate, $200 \mathrm{r} / \mathrm{min}$; contact time, $2 \mathrm{~h}$ )

In order to investigate the mechanism of adsorption, the experimental data were further analyzed using the pseudosecond-order kinetic model (eqn. 5) ${ }^{31}$ and pseudo-first-order kinetic model (eqn. 6) ${ }^{32}$, which expressed, respectively as follows:

$$
\begin{gathered}
\ln \left(\mathrm{q}_{\mathrm{e}}-\mathrm{q}_{\mathrm{t}}\right)=\ln \mathrm{q}_{\mathrm{e}}-\mathrm{k}_{1} \mathrm{t} \\
\frac{\mathrm{t}}{\mathrm{q}_{\mathrm{t}}}=\frac{1}{\mathrm{k}_{2} \mathrm{q}_{\mathrm{e}}^{2}}+\frac{\mathrm{t}}{\mathrm{q}_{\mathrm{e}}}
\end{gathered}
$$

where $\mathrm{q}_{\mathrm{e}}$ is the amount of $p$-nitrophenol adsorbed on adsorbent at equilibrium $(\mathrm{mg} / \mathrm{g}), \mathrm{q}_{\mathrm{t}}$ is the amount of $p$-nitrophenol adsorbed at various times $\mathrm{t}(\mathrm{mg} / \mathrm{g}), \mathrm{k}_{1}$ is the pseudo-first-order rate constant for the adsorption process $\left(\mathrm{h}^{-1}\right)$ and $\mathrm{k}_{2}$ is the rate constant of pseudo-second-order adsorption [g/(mg h)].

The value of $\mathrm{k}_{1}$ can be obtained from the slope of the linear plot of $\ln \left(\mathrm{q}_{\mathrm{e}}-\mathrm{q}_{\mathrm{t}}\right)$ versus $\mathrm{t}$. The calculated results and $\mathrm{R}^{2}$ were listed in Table- 3 . $\mathrm{R}^{2}$ for the first-order kinetic model was relatively low and the calculated $\mathrm{q}_{\mathrm{e}}$ values obtained from the first-order kinetic model failed to match the experimental $\mathrm{q}_{\mathrm{e}}$ values. Hence, the adsorption of $p$-nitrophenol onto soil was not a first-order reaction.

Fig. 6 depicted a good agreement of experimental data with the second-order kinetic model at different soil doses. The results obtained from the second-order kinetic model were listed in Table- $3 . \mathrm{R}^{2}$ for the second-order kinetic model at different soil doses is more than 0.999. Moreover, the calculated $\mathrm{q}_{\mathrm{e}}$ values were in reasonable agreement with the experimental data. It could be concluded that the adsorption of $p$-nitrophenol onto the variable charge soil obeyed the secondorder kinetic model. The results indicated that physical interaction is involved in the adsorption process, which may be partly ascribed to H-bonding between the hydroxyl group of $p$-nitrophenol and some active functional groups in the soil.

Analysis of SEM and FTIR spectra: The SEM photographs of the soil before and after $p$-nitrophenol adsorption were presented in Fig. 7. From the SEM micrographs (Fig. 7a), 


\begin{tabular}{ccccc|ccc}
\hline \multirow{2}{*}{ Parameters } & \multirow{2}{*}{$\mathrm{q}_{\mathrm{e}}, \exp (\mathrm{mg} / \mathrm{g})$} & \multicolumn{3}{c|}{ Pseudo-first-order } & \multicolumn{3}{c}{ Pseudo-first-order } \\
\cline { 3 - 8 } & & $\mathrm{K}_{1}\left(\mathrm{~h}^{-1}\right)$ & $\mathrm{q}_{\mathrm{e}}, \mathrm{cal}(\mathrm{mg} / \mathrm{g})$ & $\mathrm{R}^{2}$ & $\mathrm{~K}_{2}(\mathrm{~g} /(\mathrm{mg} \cdot \mathrm{h}))$ & $\mathrm{q}_{\mathrm{e}}, \mathrm{cal}(\mathrm{mg} / \mathrm{g})$ & $\mathrm{R}^{2}$ \\
\hline $1.00 \mathrm{~g}$ soil & 2.109 & 0.261 & 0.319 & 0.486 & 5.020 & 2.117 & 0.999 \\
$0.50 \mathrm{~g}$ soil & 1.595 & 0.245 & 0.162 & 0.390 & 10.699 & 1.597 & 0.999 \\
\hline
\end{tabular}

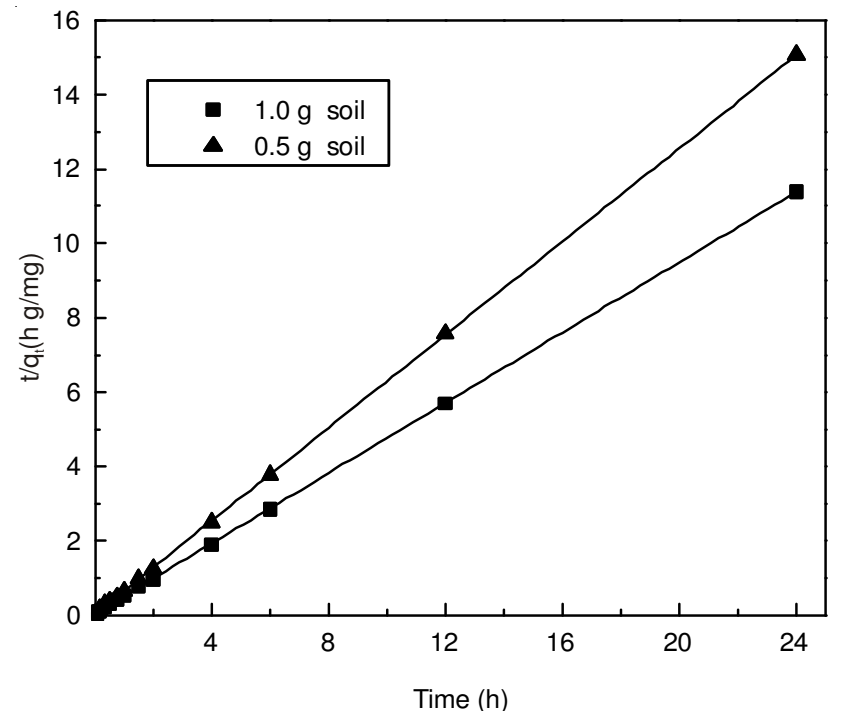

Fig. 6. Pseudo-second-order kinetic plots for the adsorption of $p$ nitrophenol onto soil at various absorbent doses

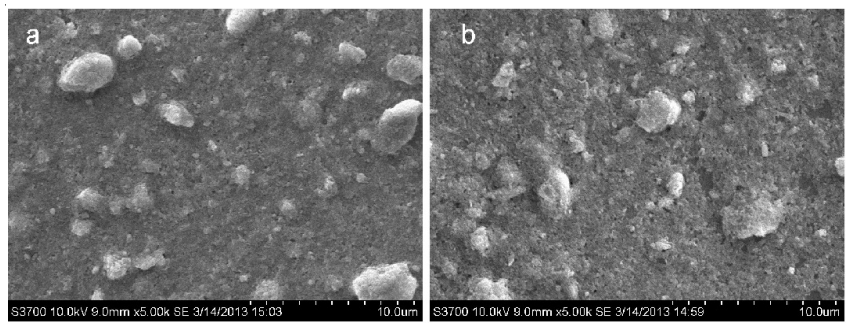

Fig. 7. SEM images (a) before and (b) after $p$-nitrophenol adsorption

it can be seen that the soil surface looked relatively smooth and clear, with several large spots on it. However, Fig. 7b showed that the surface of soil was faint and no significant spots appeared. The observed phenomenon was due to the adsorption of $p$-nitrophenol onto the soil. Fig. 8 showed the FTIR spectra of soil and $p$-nitrophenol adsorbed soil in the frequency range of $4000-500 \mathrm{~cm}^{-1}$. Fig. $8 \mathrm{a}$ was the spectra of soil before adsorption, which showed a bend at $3695 \mathrm{~cm}^{-1}$ due to asymmetric stretching of the $\mathrm{N}-\mathrm{H}$ group confirming the existence of an amino group. The peak at $3447 \mathrm{~cm}^{-1}$ was due to $\mathrm{OH}$ stretching vibrations, while the peak at $1639 \mathrm{~cm}^{-1}$, may be due to the stretching vibration of $\mathrm{C}=\mathrm{O}$ band of phenyl ring on the soil. The peaks between (700 and 1000) $\mathrm{cm}^{-1}$ assigned to $=\mathrm{C}-\mathrm{H}$ bending of alkenes ${ }^{33}$. The FTIR spectrum of soil after adsorption (Fig. 8b) showed characteristic peaks at (3621, $2362,1639,1007,913) \mathrm{cm}^{-1}$, which were similar to the peaks observed in soil before adsorption. The peaks at $3447 \mathrm{~cm}^{-1}$ was changed to 3441 and $3995 \mathrm{~cm}^{-1}$ was shifted to 3994 and $1013 \mathrm{~cm}^{-1}$ shifted to $1014 \mathrm{~cm}^{-1}$. Due to the adsorption of $p$-nitrophenol on the soil surface, a prominent peak due to $\mathrm{H}$-bonded-O-H stretch of the phenolic group was observed at $3441 \mathrm{~cm}^{-1}$. The peaks at 1527 and $1508 \mathrm{~cm}^{-1}$ are due to $\mathrm{N}=\mathrm{O}$

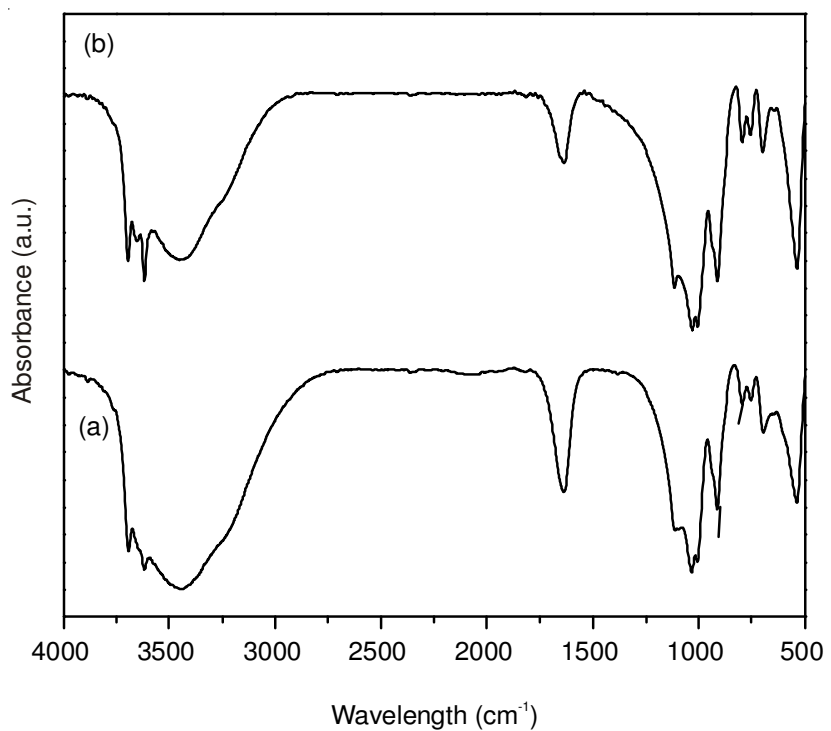

Fig. 8. FTIR spectra of $p$-nitrophenol sorbed on soil in the $4000-500 \mathrm{~cm}^{-1}$ region (a) before and (b) after $p$-nitrophenol adsorption

stretching, while that at $1460 \mathrm{~cm}^{-1}$ was due to $\mathrm{N}=\mathrm{O}$ bending of the nitro group. Presences of these bands were responsible for the adsorption of $p$-nitrophenol.

\section{Conclusion}

This research studied the behaviour and mechanism of the adsorption of $p$-nitrophenol from aqueous solutions onto variable charge soil. It was observed that the initial solution $\mathrm{pH}, \mathrm{KNO}_{3}$ content, adsorbent dosage, heavy metal ions and temperature had an influence on the adsorption of $p$-nitrophenol. Adsorption of $p$-nitrophenol decreased with increasing the solution $\mathrm{pH}$, whereas it increased with increasing $\mathrm{KNO}_{3}$ content, temperature and adsorbent dosage and the presence of heavy metal ions depressed the adsorption of $p$-nitrophenol. Langmuir and Freundlich models were used to describe the adsorption isotherms. Freundlich model was fit to experimental data well, which suggested the possibility of more than just one monomolecular layer of coverage on the soil surface. The pseudo-first-order and pseudo-second-order kinetic model were applied to describe the kinetic data. The experimental data obeyed the pseudo-second-order kinetic model. SEM micrographs detect some morphological change before and after the adsorption of $p$-nitrophenol on the surface of soil and FTIR also proved some bands changed before and after the adsorption of $p$-nitrophenol on the surface of soil.

\section{ACKNOWLEDGEMENTS}

This research was financially supported by the National Nature Science Foundation of China (Nos. 51078148 and 41173103). 


\section{REFERENCES}

1. M. Bielska and J. Szymanowski, J. Membr. Sci., 243, 273 (2004).

2. S. Dutta, J.K. Basu and R.N. Ghar, Sep. Purif. Technol., 21, 227 (2001).

3. J. Tremp, P. Mattrel, S. Fingler and W. Giger, Water, Air, Soil Pollut., 68, 113 (1993).

4. J.S. Zhang, Z.T. Sun, Y. Li, X. Peng, W. Li and Y. Yan, J. Hazard. Mater, 163, 723 (2009).

5. W. Sun, M.X. Yang, Q. Jiang and K. Jiao, Chin. Chem. Lett., 19, 1156 (2008).

6. P.H. Zhang, Y.M. Sui, G.J. Xiao, Y.N. Wang, C.Z. Wang, B.B. Liu, G.T. Zou and B. Zou, J. Mater. Chem., 1, 1632 (2013).

7. M. Sugiyama, Z. Salehi, M. Tokumura and Y. Kawase, Water Sci. Technol., 65, 1882 (2012).

8. E. Suja, Y.V. Nancharaiah and V.P. Venugopalan, Appl. Biochem. Biotechnol., 167, 1569 (2012).

9. T.R. Bastami and M.H. Entezari, Chem. Eng. J., 210, 510 (2012).

10. S. Nouri and F. Haghseresht, Adsorption, 10, 79 (2004).

11. Y. Park, R.L. Frost, G.A. Ayoko and D.L. Morgan, J. Therm. Anal. Calorim., 111, 41 (2013).

12. Y. Chang, X.Q. Lv, F. Zha, Y.G. Wang and Z.Q. Lei, J. Hazard. Mater. 168, 826 (2009).

13. B. Sarkar, M. Megharaj, X.F. Xi and R. Naidu, Chem. Eng. J., 185, 35 (2012).

14. X.Y. Shen, W.F. Huang, C.Y. Yao and S.T. Ying, Chemosphere, 67, 1927 (2007).

15. W.F. Huang, C.Y. Yao, S.J. Jin, S.T. Ying and X.Y. Shen, J. Hazard. Mater., 155, 225 (2008).
16. S. Yu, Z.L. He, C.Y. Huang, G.C. Chen and D.V. Calvert, Geoderma, 123, 163 (2004).

17. R. Naidu, M.E. Sumner and R.D. Harter, Environ. Geochem. Health, 20, 5 (1998).

18. J. Jiang, Y. Wang, R.K. Xu and C. Yang, Environ. Earth Sci., 66, 1155 (2008).

19. J. Liang, R.K. Xu, X. Jiang, Y. Wang, A. Zhao and W.F. Tan, Chemosphere, 67, 1949 (2007).

20. H.Q. Hu, H.L. Liu, H.J. Zhang and Q.Y. Huang, Pedosphere, 17, 117 (2007).

21. J. Jiang, Y. Wang, R.K. Xu and C. Yang, Environ. Earth Sci., 66, 1155 (2012).

22. S. Yu, Z.L. He, C.Y. Huang, G.C. Chen and D.V. Calvert, Biogeochemistry, 75, 1 (2005).

23. R.K. Xu, Y. Wang, D. Tiwari and H.Y. Wang, J. Environ. Sci., 21, 927 (2009).

24. B.M. Babic, S.K. Milonjic, M.J. Polovina and B.V. Kaludierovic, Carbon, 37, 477 (1999).

25. A. Turner and M.C. Rawling, Water Res., 35, 4379 (2001).

26. D.Y. Tang, Z. Zheng, K. Lin, J.F. Luan and J.B. Zhang, J. Hazard. Mater, 143, 49 (2007).

27. P.K. Chaturvedi, C.S. Seth and V. Misra, Chemosphere, 64, 1109 (2006).

28. V.K. Gupta, I. Ali and V.K. Saini, Environ. Sci. Technol., 38, 4012 (2004).

29. S.H. Lin and C.Y. Huang, J. Hazard. Mater, 70, 21 (1999).

30. I. Langmuir, J. Am. Chem. Soc., 38, 2221 (1916).

31. Y.S. Ho and G. McKay, Chem. Eng. J., 70, 115 (1998).

32. F. Akbal, J. Colloid Interf. Sci., 286, 455 (2005).

33. M. Ahmaruzzaman and S.L. Gayatri, J. Chem. Eng. Data, 55, 4614 (2010). 